\title{
PERBANDINGAN METODE AUTOREGRESSIVE INTEGRATED MOVING AVERAGE DAN METODE DOUBLE EXPONENTIAL SMOOTHING DARI HOLT DALAM MERAMALKAN NILAI IMPOR DI INDONESIA
}

\author{
Yulinar I. Ajunu ${ }^{1}$, Novianita Achmad ${ }^{2}$, Muhammad Rezky Friesta Payu ${ }^{3}$ \\ ${ }^{1,3}$ Program Studi Statistika, Fakultas Matematika dan IPA, Universitas Negeri Gorontalo \\ ${ }^{2}$ Program Studi Matematika, Fakultas Matematika dan IPA, Universitas Negeri Gorontalo
}

e-mail: ayu13jun@gmail.com

\begin{abstract}
Abstrak
Impor merupakan pembelian barang yang dilakukan oleh suatu negara kepada negara lain. Impor memiliki dampak positif dan negatif untuk suatu negara, oleh karena itu perlu dilakukan peramalan. Metode peramalan yang digunakan yaitu Metode ARIMA dan Metode Double Exponential Smoothing dari Holt. Tujuan dari penelitian ini adalah untuk melihat metode terbaik dalam meramalkan Nilai Impor di Indonesia. Tahapan Penelitian Metode ARIMA yaitu Plot data, Stasionerkan data, Identifikasi model sementara, Estimasi parameter, Uji asumsi residual, dan Peramalan. Tahapan Penelitian Metode Double Exponential Smoothing dari Holt yaitu Plot data, Menentukan nilai awal, Mencari parameter optimal, Menghitung nilai Level $(L t)$ dan Trend $(T t)$ dan melakukan Peramalan. Kesimpulan yang didapat adalah metode ARIMA merupakan metode yang terbaik dalam meramalkan Nilai Impor di Indonesia.
\end{abstract}

Kata Kunci: ARIMA, Pemulusan Eksponensial, Impor, MAPE, Peramalan

\begin{abstract}
As a form of purchased goods from other state's imports have impacts both positive and negative to the states's condition; therefore, prediction is required. Employing Autoregressive Integrated Moving Average (ARIMA) and Holt's Double Exponential Smoothing (DES) methods, this study intends to identify which of the methods is the most accurate to predict Indonesia's import value. The ARIMA method stage involved: data ploting, data stasioneriation, temporary model identification, parameter estimation, test residual assumption, and prediction. Moreover, the Holt's DES method involved: data plotting, initial value determination, optimal parameter identification, Level $L_{t}$ and Trend $T_{t}$ value quantification, andprediction. The result shows that ARIMA method is the most accurate method to predict Indonesia's import value.
\end{abstract}

Keywords: ARIMA, Exponential Smoothing, Import, MAPE, Forecasting.

\section{PENDAHULUAN}

Peramalan merupakan suatu usaha untuk memprediksi keadaan di masa mendatang berdasarkan keadaan di masa lalu. Data masa lalu dikumpulkan, dipelajari, dianalisis dan dihubungkan dengan waktu. Berdasarkan data hasil analisis tersebut diperoleh estimasi/pendekatan mengenai apa yang akan terjadi di masa yang akan datang (Heizer and Render 2014)

Dalam peramalan Terdapat dua pendekatan yaitu peramalan kualitatif dan kuantitatif. Pendekatan peramalan yang digunakan yaitu peramalan kuantitatif. di dalam metode peramalan kuantitatif terdapat dua jenis peramalan yaitu Peramalan Kausal dan 
Peramalan Time series. Time series adalah data yang dikumpulkan dari waktu ke waktu berupa harian, mingguan, bulanan dan tahunan untuk menggambarkan suatu peristiwa atau keadaan tertentu (Makridakis et al. 1998). Analisis Time series merupakan serangkaian pengamatan yang terjadi secara berurutan pada interval waktu yang tetap (Wei 2006)

ARIMA merupakan salah satu analisis dalam time series, ARIMA sering juga disebut metode Box-Jenkins, ARIMA digunakan dalam penelitian untuk meramalkan data masa yang akan datang berdasarkan perilaku data di masa lalu. ARIMA juga sangat baik ketepatannya dalam peralaman jangka pendek, sedangkan untuk peramalan jangka panjang ketepatan peramalannya kurang baik. Secara harfiah, model ARIMA merupakan gabungan antara model AR (Autoregressive) dan model MA (Moving Average) (Ekananda 2016).

Selain ARIMA, salah satu metode yang digunakan adalah Metode Double Exponential Smoothing (DES) dari Holt dalam prinsipnya serupa dengan DES dari Brown dimana Holt tidak menggunakan rumus pemulusan berganda secara langsung, tetapi Holt memuluskan nilai trend dengan parameter yang berbeda dari parameter yang digunakan pada deret yang asli. Metode DES dari Holt digunakan untuk meramalkan data masa yang akan datang berdasarkan data masa lalu atau sering disebut data historis dan juga metode ini lebih baik ketepatannya dalam peramalan jangka pendek. Proses inisialisasi untuk DES dari Holt memerlukan dua parameter, yang satu mengambil nilai pemulusan pertama untuk Lt dan yang lain mengambil trend $\mathrm{Tt}$ (Makridakis et al. 1998).

Alasan peneliti memilih dua metode di atas karena peneliti ingin melihat manakah hasil peramalan yang terbaik untuk meramalkan Nilai Impor di Indonesia, dimana metode ARIMA bisa digunakan untuk semua jenis pola data dibandingkan dengan

DES dari Holt yang syaratnya harus menggunakan jenis pola data trend. Hal ini telah memenuhi asumsi bahwa jenis pola datanya trend. Selain itu, jangka peramalan yang digunakan yaitu jangka pendek, dan juga data yang digunakan berdasarkan data historis dan menjadi acuan untuk peramalan.

Salah satu permasalahan yang bisa diteliti menggunakan time series adalah nilai impor. Impor merupakan pembelian barang yang dilakukan oleh suatu negara kepada negara lain. Impor dapat terjadi karena suatu negara tidak bisa menghasilkan barangbarang tertentu untuk keperluan pengembangan negara tersebut. tanpa dilakukannya impor maka kebutuhan produksi suatu negara tidak dapat terpenuhi (Sukirno 2012). Sedangkan Nilai impor merupakan salah satu tolak ukur untuk melihat bagaimana kondisi perekonomian suatu Negara sehingga dapat digunakan sebagai acuan untuk melihat apakah perekonomian suatu Negara stabil atau tidak. Nilai impor juga menunjukan tingkat produktivitas suatu Negara, nilai impor yang tinggi akan mengakibatkan produktivitas dalam negeri menurun sehingga dapat meningkatkn pengangguran (Sedyaningrum and Nuzula 2016).

Penelitian relevan yang digunakan peneliti adalah (Mahmudi et al. 2018) yang membahas tentang peramalan inflasi menggunakan DES serta (Hartati 2017) yang membahas tentang peramalan pergerakan inflasi menggunakan metode ARIMA. Dari uraian diatas, maka peneliti memilih membandingkan metode ARIMA dan metode DES. Selanjutnya kedua model tersebut diaplikasikan pada data nilai impor indonesia.

\section{METODE PENELITIAN}

Metode yang digunakan dalam penelitian ini adalah studi literatur dengan menelusuri jurnaljurnal dan buku teks yang terkait dengan Model ARIMA dan Model DES. Penelitian ini menggunakan data bulanan Nilai Impor di Indonesia yang terhitung sejak tahun 2015-2018. 
Adapun tahapan penelitian adalah sebagai berikut:

a. Metode ARIMA

1. Plot Data Faktual

2. Pengujian kestasioneran dalam mean menggunakan ujiADF (Augmented Dickey Fuller)

3. Melakukan differencing jika data tidak stasioner dalam mean

4. Melakukan identifikasi model sementara berdasarkan hasil dari plot ACF \& PACF

5. Melakukan estimasi parameter dan menguji signifikansi parameter model ARIMA sementara

6. Menguji asumsi residual dengan menggunakan pengujian White Noise dan pemeriksaan Distribusi Normal

7. Melakukan peramalan data faktual

b. Metode DES Holt

1. Plot Data Faktual

2. Menentukan nilai awal pemulus

3. Mencari parameter optimal

4. Menghitung nilai $L_{t}$ dan $T_{t}$

5. Melakukan peramalan

Selanjutnya disajikan beberapa definisi dasar yang digunakan pada penelitian ini.

Definisi 1 (Model ARIMA(p,q)) (Zivot and Wang 2006) Misalkan $y_{t}$ adalah data observasi dan $\mu$ adalah mean dari proses $y_{t}$ maka $y_{t}$ disebut proses ARIMA $(\mathrm{p}, \mathrm{q})$ jika memenuhi persamaan (1).

$$
y_{t}-\mu=\phi_{1}\left(y_{1}-\mu\right)+\cdots+\phi_{p}\left(y_{p}-\mu\right)+\varepsilon_{t}+\theta_{1} \varepsilon_{t-1}+\cdots+\theta_{p} \varepsilon_{t-p}
$$

Dimana $\varepsilon_{t} \sim W N\left(0, \sigma^{2}\right)$

Definisi 2 (Model DES)) (Yaffee and McGee 2000) Misalkan $y_{t}$ adalah data observasi maka $y_{t}$ disebut proses DES jika memenuhi persamaan (2), (3) dan (4).

$$
\begin{gathered}
L_{t}=\alpha X_{t}+(1-\alpha)\left(L_{t-1}+T_{t-1}\right) \\
T_{t}=\beta\left(L_{t}-L_{t-1}\right)+(1-\beta) T_{t-1}, \\
F_{t+m}=L_{t}+T_{t}(m)
\end{gathered}
$$

dengan,

$L_{t} \quad=$ nilai pemulusan pada periode ke $\mathrm{t}$.

$L_{t-1} \quad=$ nilai pemulusan pada periode ke $\mathrm{t}-1$

$X_{t} \quad=$ data factual time series pada periode ke $\mathrm{t}$

$T_{t} \quad=$ nilai trend periode ke $\mathrm{t}$

$T_{t-1}=$ nilai trend periode ke $\mathrm{t}-1$

$\alpha, \beta=$ parameter pemulusan, $(0<\alpha<1)$ dan $(0<\beta<1)$

$F_{t+m}=$ hasil peramalan untuk periode ke depan

Definisi 3 (Mean Absolute Percentage Error) (Armstrong 2001) MAPE adalah ukuran ketepatan ramalan yang merupakan Rata-rata jumlah dari semua persentase kesalahan untuk sebuah set data, diambil tanpa memperhatikan tanda. Dapat dirumuskan pada Persamaan (5). 


$$
M A P E=\frac{1}{n} \sum_{i=1}^{n} \frac{\left|Z_{t}-F_{t}\right|}{Z_{t}} \times 100 \%
$$

dengan,

$Y_{t} \quad$ = banyaknya observasi

$F_{t} \quad=$ ramalan

\section{HASIL DAN PEMBAHASAN}

\subsection{Analisis time series dengan metode ARIMA}

Seperti yang telah dijelaskan pada bagian 2. Langkah pertama pada analisis time series dengan ARIMA adalah plot data faktual.Plot data nilai impor di Indonesia ditampilkan pada gambar 1 .

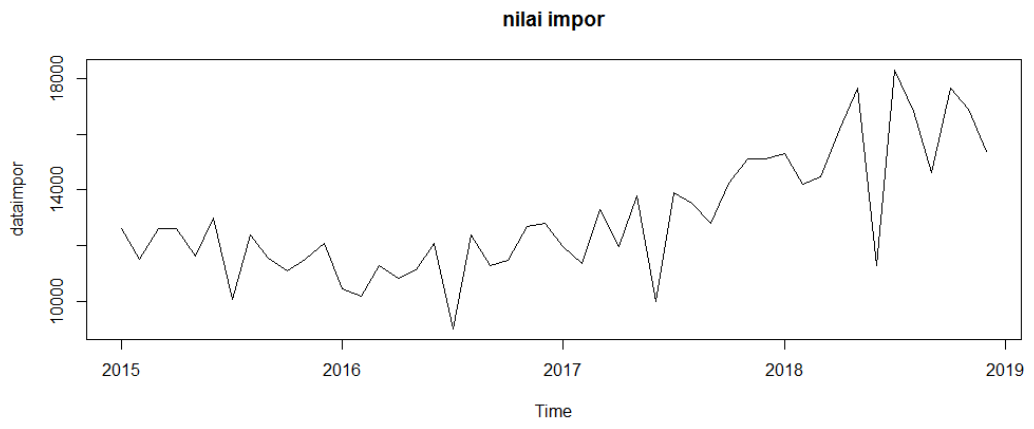

Gambar 1 Plot data trend

Gambar 1 menunjukkan bahwa data nilai impor di Indonesia cenderung mengalami peningkatan dari waktu ke waktu yang mengindikasikan bahwa terdapat unsur trend dalam data yaitu trend naik. Selanjutnya adalah uji stasioneritas data, metode yang digunakan yaitu Augmented Dickey Fuller (ADF), dengan hipotesis sebagai berikut:

$\mathrm{H}_{0} \quad$ : data tidak stasioner

$\mathrm{H}_{1}$ : data stasioner

untuk menentukan apakah menerima atau menolak hipotesis nol (Enders 2004). Aturan keputusan diambil berdasarkan criteria berikut:

a. Jika statistik-t lebih besar dari DF atau $p$-value lebih besar dari $\alpha=0,05$ maka terima $\mathrm{H}_{0}$ dan disimpulkan $Z_{t}$ mempunyai akar unit atau $Z_{t}$ tidak stasioner.

b. Jika statistik-t lebih kecil dari DF atau $p$-value lebih besar dari $\alpha=0,05$ maka tolak $\mathrm{H}_{0}$ dan disimpulkan $Z_{t}$ tidak mempunyai akar unit atau $Z_{t}$ stasioner.

Setelah dilakukan analisis didapatkan nilai $p$-value dari data impor di Indonesia yaitu 0,5613 dimana p-value lebih besar dari nilai $\alpha$ yaitu 0,05 . hal ini menunjukan bahwa $\mathrm{H}_{0}$ diterima, dimana menunjukan data nilai impor di Indonesia tidak stasioner atau tidak konstan dalam mean, maka dilakukan diferensiasi data. Setelah dilakukan diferensiasi orde pertama data telah stastioner dengan dilakukan uji ADF kembali nilai p-value dari ADF test yaitu 0,01, dimana $p$-value lebih kecil dari $\alpha$ $=0,05$ yang berarti $\mathrm{H}_{0}$ ditolak, dimana menunjukan data nilai impor di Indonesia telah stasioner dalam rata-rata.

Identifikasi model sementara dapat dilihat dari plot ACF dan PACF. Pada tahapan ini dilakukan plot data hasil diferensiasi pertama, berikut plot ACF dan PACF data nilai impor: 

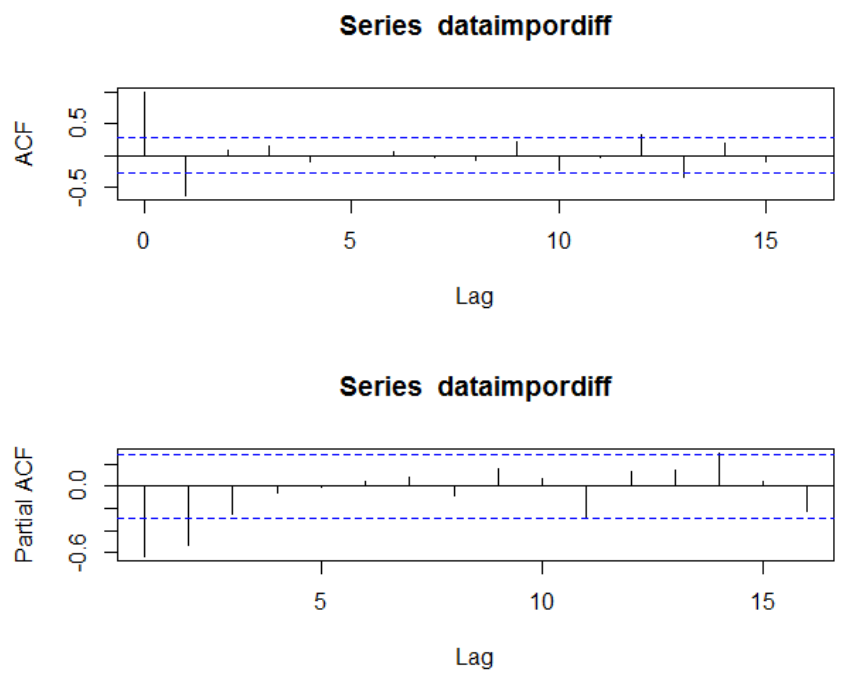

Gambar 2 Plot ACF dan PACF hasil diferensiasi pertama

Berdasarkan Gambar 2, pada plot ACF terjadi cut off pada lag pertama dan kedua. Selanjutnya pada plot PACF naik secara eksponensial. Maka model sementara yang terbentuk berdasarkan plot ACF dan PACF yaitu ARIMA $(0,1,1)$ dan ARIMA $(0,1,2)$.

Selanjutnya dilakukan uji signifikansi parameter dalam model. Pengujian hipotesis parameter sebagai berikut:

$H_{0}: \emptyset_{i}=0$ atau $\theta_{j}=0$ (parameter tidak signifikan dalam model)

$H_{1}: \emptyset_{i}=0$ atau $\theta_{j}=0$ (parameter signifikan dalam model)

Dengan, $i=1,2,3 \ldots p$ dan $j=1,2,3 \ldots q$ dan Statistik uji $: t_{\text {hitung }}=\frac{\widehat{\varnothing}}{s e(\widehat{\varnothing})}$ atau $t_{\text {hitung }}=$ $\frac{\widehat{\theta}}{\operatorname{se}(\widehat{\theta})}$

Dimana:

$$
\begin{aligned}
& \widehat{\emptyset} \text { atau } \hat{\theta}=\text { estimasi parameter pada model } \\
& n \quad=\text { banyaknya data } \\
& p \text { dan } q=\text { banyaknya parameter dalam model }
\end{aligned}
$$

daerah kritis $=\left|t_{\text {hitung }}\right|>t_{\frac{\alpha}{2} \text { in }-p}$ atau jika nilai $p_{\text {value }}<\alpha=5 \%$ pengambilan keputusan jika $H_{0}$ ditolak maka parameter signifikan terhadap model (Wahyuningsih et al. 2017).

Berikut akan disajikan tabel estimasi parameter dan uji signifikansi parameter model-model yang terbentuk :

Tabel 1 Model ARIMA $(0,1,1)$

\begin{tabular}{|c|c|c|c|c|c|}
\hline Parameter & Koefisien & S.E & $\left|\mathbf{T}_{\text {hitung }}\right|$ & $\mathbf{T}_{\text {tabel }}$ & Keterangan \\
\hline MA1 & $-0,7194$ & 0,0701 & 10,26 & 1,67 & Signifikan \\
\hline
\end{tabular}


Tabel 2 Model ARIMA $(0,1,2)$

\begin{tabular}{|c|c|c|c|c|c|}
\hline Parameter & Koefisien & S.E & $\mid$ Thitung $\mid$ & Ttabel $_{\text {Keterangan }}$ & Signifikan \\
\hline MA1 & $-1,2248$ & 0,1053 & 11,63 & 1,67 & Signifikan \\
\hline MA2 & 0,6917 & 0,1491 & 4,63 & 1,67 & \\
\hline
\end{tabular}

Berdasarkan dari tabel 1 dan tabel 2, semua parameter yang terdapat dalam model ARIMA adalah signifikan. Sehingga semua model dapat dilanjutkan pada tahapan berikutnya yaitu uji asumsi residual.

Untuk memeriksa asumsi residual dengan menggunakan pengujian white noise dan pengujian distribusi normal. pada pengujian white noise digunakan uji Ljung-Box, dengan hipotesis sebagai berikut:

$H_{0}: \rho_{1}=\rho_{2}=\cdots=\rho_{k}=0$ (residual memenuhi asumsi white noise)

$H_{1}$ : minimal ada satu $\rho_{1}$ yang tidak sama dengan nol, $\mathrm{i}=1,2,3 \ldots, \mathrm{K}$ (residual tidak memenuhi asumsi white noise).

Statistik uji :

$$
Q=n(n+2) \sum_{k=1}^{K} \frac{\hat{\rho} k^{2}}{(n-k)}
$$

Dengan,

$n$ = banyaknya pengamatan

$\hat{\rho}_{k}=$ sampel ACF residual pada lag ke $\mathrm{k}$

$\mathrm{k} \quad=$ jumlah maksimum lag

daerah kritis $=Q>X^{2}(1-\alpha):(k-m)$ atau $p_{\text {value }}<\alpha=5 \%$ pengambilan keputusan jika $H_{0}$ ditolak maka residual tidak memenuhi asumsi white noise (Wahyuningsih et al. 2017)

Tabel 3 Uji Asumsi White Noise

\begin{tabular}{|c|c|c|c|}
\hline No & Model & P-Value & Asumsi White Noise \\
\hline 1 & Model ARIMA $(0,1,1)$ & 0,01027 & Residual Tidak Memenuhi Asumsi White Noise \\
\hline 2 & Model ARIMA $(0,1,2)$ & 0,7781 & Residual Memenuhi Asumsi White Noise \\
\hline
\end{tabular}

Berdasarkan tabel 3, model yang memenuhi Asumsi White noise yaitu ARIMA $(0,1,2)$ karena $p$ value lebih besar dari nilai $\alpha=0,05$. Tahapan selanjutnya yaitu Uji normalitas residual. Uji ini dilakukan untuk mendeteksi kenormalan residual model. Dalam penelitian ini uji yang digunakan yaitu Kolmogorov Smirnov, dengan hipotesis sebagai berikut:

$H_{0}: F\left(a_{t}\right)=F_{0}\left(a_{t}\right)$ (residual berdistribusi normal)

$H_{1}: F\left(a_{t}\right) \neq F_{0}\left(a_{t}\right)$ (residual tidak berdistribusi normal)

Statistik uji :

$$
D=\sup \left|S\left(a_{t}\right) F_{0}\left(a_{t}\right)\right|
$$


Daerah kritis : tolak $H_{0}$ jika $p_{\text {value }}<\alpha=5 \%$, pengambilan keputusan, jika $H_{0}$ ditolak maka residual tidak berdistribusi normal (Wahyuningsih et al. 2017). Hasilnya diperoleh pada tabel 4.

Tabel 4 Uji Kolmogorov Smirnov

\begin{tabular}{|c|c|c|c|}
\hline No & Model & P-Value & Asumsi White Noise \\
\hline 1 & Model ARIMA $(0,1,1)$ & 0,923 & Residual Berdistribusi Normal \\
\hline
\end{tabular}

Tabel 4 memberikan hasil bahwa model terbaik adalah model ARIMA $(0,1,1)$. Model ini selanjutnya akan digunakan pada peramalan data nilai impor.

Setelah mendapatkan model terbaik maka langkah selanjutnya yaitu melakukan peramalan dengan model terbaik, Tabel 5 hasil ramalan selama 12 bulan terhitung dari Januari 2019 Sampai dengan Desember 2019:

Tabel 5 Hasil Ramalan Tahun 2019

\begin{tabular}{|c|c|c|c|}
\hline Bulan & Ramalan & Faktual & Error \\
\hline Januari 2019 & $17.432,55$ & $15.028,5$ & $2.404,05$ \\
\hline Februari 2019 & $16.528,79$ & $12.202,1$ & $4.326,69$ \\
\hline Maret 2019 & $16.528,79$ & $13.486,2$ & $3.042,59$ \\
\hline April 2019 & $16.528,79$ & $15.098,8$ & $1.430,79$ \\
\hline Mei 2019 & $16.528,79$ & $14.534,2$ & $1.994,59$ \\
\hline Juni 2019 & $16.528,79$ & $11.583,8$ & $4.944,99$ \\
\hline Juli 2019 & $16.528,79$ & $15.514,2$ & $1.014,59$ \\
\hline
\end{tabular}

Berdasarkan Tabel 5, hasil peramalan pada bulan Januari sebesar 17.432,55 Juta US\$. lalu pada bulan Februari sampai dengan bulan Juli mengalami penurunan yaitu sebesar 16.528,79 Juta US\$. Apabila nilai impor ramalan dibandingkan dengan nilai impor faktualnya, maka akan didapatkan nilai selisih yang besar terdapat pada bulan Juni yaitu 4.944,99. Sedangkan untuk selisih nilai impor ramalan dan nilai impor faktual yang kecil terdapat pada bulan April yaitu 1.430,79. Sehingga dapat disimpulkan bahwa nilai hasil ramalan tidak sama persis dengan nilai faktualnya. Tetapi pergerakan nilai impor ramalan memiliki kecenderungan mengikuti pergerakan nilai impor faktualnya.

\subsection{Analisis Time Series Dengan Metode DES dari Holt}

Sesuai bahasan pada bagian 2, langkah pertama pada pemodelan DES adalah Inisialisasi awal. Pada penelitian ini, Inisialisasi awal pada software R telah terprogram dalam fungsi Holtwinter. Rumusan inisialisasi awal dituliskan pada persamaan (6) dan (7) (Holt 2004).

$$
\begin{gathered}
\mathrm{L}_{1}=\mathrm{X}_{1} \\
\mathrm{~T}_{1}=\left(\mathrm{X}_{2}-\mathrm{X}_{1}\right)
\end{gathered}
$$

Selanjutnya adalah pengoptimalan paramameter Pengoptimalan Parameter dapat dilakukan dengan cara trial and error, akan tetapi cara ini menyita waktu, maka untuk mendapatkan parameter yang optimal dilakukan dengan bantuan Software R. 
Tabel 6 Pengoptimalan Parameter

\begin{tabular}{|c|c|}
\hline Parameter $\boldsymbol{\alpha}$ & Parameter $\beta$ \\
\hline 0,2467443 & 0,4556766 \\
\hline
\end{tabular}

Tabel 6 adalah tabel hasil pengoptimalan paramater. Hasil pengoptimalan paramater diperoleh hasil nilai parameter alpha $=0,2467443$ dan beta $=0,4556766$.

Setelah parameter optimal telah didapatkan maka selanjutnya melakukan Peramalan Dengan Metode DES Dari Holt. Berikut tabel hasil ramalan selama 12 bulan terhitung dari Januari 2019 Sampai dengan Desember 2019.

Tabel 7 Hasil Ramalan Tahun 2019

\begin{tabular}{|c|c|c|c|}
\hline Bulan & Ramalan & Faktual & Error \\
\hline Januari 2019 & $16.600,45$ & $15.028,5$ & $1.571,95$ \\
\hline Februari 2019 & $16.628,81$ & $12.202,1$ & $4.427,71$ \\
\hline Maret 2019 & $16.657,17$ & $13.486,2$ & $3.170,97$ \\
\hline April 2019 & $16.685,53$ & $15.098,8$ & $1.587,73$ \\
\hline Mei 2019 & $16.713,89$ & $14.534,2$ & $2.180,69$ \\
\hline Juni 2019 & $16.742,24$ & $11.583,8$ & $5.159,44$ \\
\hline Juli 2019 & $16.770,60$ & $15.514,2$ & $1.257,4$ \\
\hline
\end{tabular}

Berdasarkan Tabel 7, hasil peramalan pada bulan Januari sampai dengan bulan Juli mengalami kenaikan setiap bulannya. Apabila nilai impor ramalan dibandingkan dengan nilai impor faktualnya, maka akan didapatkan nilai selisih yang besar terdapat pada bulan Juni yaitu 5.159,44. Sedangkan untuk selisih nilai impor ramalan dan nilai impor faktual yang kecil terdapat pada bulan Juli yaitu 1.257,4. Sehingga dapat disimpulkan bahwa nilai hasil ramalan tidak sama persis dengan nilai faktualnya. Tetapi pergerakan nilai impor ramalan memiliki kecenderungan mengikuti pergerakan nilai impor faktualnya.

\subsection{Ukuran Ketepatan Peramalan}

Selanjutnya kedua model akan diukur ketepatan peramalan dengan mengunakan MAPE. Adapun kriteria nilai MAPE disajikan pada tabel 8 (Chang et al. 2007).

Tabel 8 Kriteria nilai MAPE untuk evaluasi peramalan

\begin{tabular}{|l|l|}
\hline$M A P E \leq 10 \%$ & Sangat Baik \\
\hline $10 \%>M A P E \leq 20 \%$ & Baik \\
\hline $20 \%>M A P E \leq 50 \%$ & Cukup Baik \\
\hline$M A P E>50 \%$ & Buruk \\
\hline
\end{tabular}


Tabel 8 menunjukkan bahwa jika MAPE dibawah $10 \%$ maka dapat dikatakan model sangat baik. Sebaliknya jika sudah lebih dari 50\% maka kinerja model dalam peramalan buruk.

Selanjutnya dihitung MAPE dari model ARIMA $(0,1,2)$ dan model DES. Hasilnya diperoleh pada tabel 9.

Tabel 9 Tabel hasil MAPE dari Masing-Masing Model
\begin{tabular}{|c|c|}
\hline MAPE Model ARIMA (0,1,2) & 10,04464 \\
\hline MAPE Model DES & 7,622499 \\
\hline
\end{tabular}

Berdasarkan Tabel 9, Nilai MAPE Model ARIMA $(0,1,2)$ sebesar 7,622499, artinya nilainya kurang dari $10 \%$ sehingga dapat dikatakan bahwa kinerja model sangat baik. Sedangkan nilai MAPE model DES yaitu sebesar 10,04464, artinya nilainya lebih dari 10\% sehingga dapat dikatakan bahwa kinerja model baik.

\section{KESIMPULAN}

Berdasarkan hasil penelitian yang dilakukan dapat disimpulkan bahwa Metode yang terbaik dalam meramalkan Nilai Impor di Indonesia adalah metode ARIMA, dikarenakan nilai MAPE pada metode ARIMA sebesar 7,622499 dan nilai MAPE pada metode DES dari Holt sebesar 10,04464. Hasil ini memperlihatkan bahwa dalam melakukan peramalan nilai impor Indonesia sebaiknya menggunakan model ARIMA dibanding Model DES.

\section{DAFTAR PUSTAKA}

Armstrong, J. S. (ed.) (2001), Principles of forecasting: a handbook for researchers and practitioners, International series in operations research \& management science, Boston, MA: Kluwer Academic.

Chang, P.-C., Wang, Y.-W., and Liu, C.-H. (2007), "The development of a weighted evolving fuzzy neural network for PCB sales forecasting," Expert Systems with Applications, 32, 86-96. https://doi.org/10.1016/j.eswa.2005.11.021.

Ekananda, M. (2016), Analisis Ekonometrika Dan Analisis Time Series, Jakarta: Mitra Wacana Media.

Enders, W. (2004), Applied econometric time series, Wiley series in probability and mathematical statistics, Hoboken, NJ: J. Wiley.

Hartati, H. (2017), "PENGGUNAAN METODE ARIMA DALAM MERAMAL PERGERAKAN INFLASI,” Jurnal Matematika Sains dan Teknologi, 18, 1-10. https://doi.org/10.33830/jmst.v18i1.163.2017.

Heizer, J., and Render, B. (2014), Operations management: sustainability and supply chain management, Boston: Pearson.

Holt, C. C. (2004), "Forecasting seasonals and trends by exponentially weighted moving averages," International Journal of Forecasting, 20, 5-10. https://doi.org/10.1016/j.ijforecast.2003.09.015.

Mahmudi, M., Irwandi, R., Rahmadaini, R., and Fadhilah, R. (2018), "Meramalkan Laju Inflasi Menggunakan Metode Pemulusan Eksponensial Ganda," Journal of Data Analysis, 1, 12-20. https://doi.org/10.24815/jda.v1i1.11863.

Makridakis, S. G., Wheelwright, S. C., and Hyndman, R. J. (1998), Forecasting: methods and applications, New York: John Wiley \& Sons. 
Sedyaningrum, M., and Nuzula, N. F. (2016), "pengaruh Jumlah Nilai Ekspor, Impor dan Pertumbuhan Ekonomi terhadap Nilai Tukar dan Daya Beli Masyarakat di Indonesia," Jurnal Administrasi Bisnis, 34.

Sukirno, S. (2012), Makroekonomi: Teori pengantar, Jakarta: Raja Graffindo.

Wahyuningsih, N., Suprapti H., S., and Amutu, S. D. (2017), "Model peramalan Plywood PT. Linggar JatiMahardika Mulia," Malang: UIN Malang, pp. 52-57.

Wei, W. W. S. (2006), Time series analysis: univariate and multivariate methods, Boston: Pearson Addison Wesley.

Yaffee, R. A., and McGee, M. (2000), Introduction to time series analysis and forecasting: with applications in SAS and SPSS, San Diego: Academic Press.

Zivot, E., and Wang, J. (2006), Modeling financial time series with S-plus, New York, NY: Springer. 